\title{
Determinants of knowledge, attitude and practice in patients with both type 2 diabetes and chronic kidney disease in Fiji
}

\section{[version 1; peer review: 1 approved, 1 approved with}

\section{reservations]}

\author{
Mohammed Alvis Zibran, Masoud Mohammadnezhad (D) \\ School of Public Health and Primary Care, Fiji National University, Suva, Fiji
}

\begin{tabular}{l} 
V1 First published: 01 Mar 2019, 8:239 \\
https://doi.org/10.12688/f1000research.18188.1 \\
Second version: 16 Apr 2019, 8:239 \\
https://doi.org/10.12688/f1000research.18188.2 \\
Latest published: 01 May 2019, 8:239 \\
https://doi.org/10.12688/f1000research.18188.3 \\
\hline
\end{tabular}

\section{Abstract}

Background: In Fiji, Type 2 diabetes mellitus (T2DM) and Chronic kidney disease (CKD) are amongst the top four causes of premature mortality, disability and death. This study aims to identify the determinants of knowledge, attitude and practice (KAP) in T2DM patients with CKD in Fiji in 2018.

Methods: A cross-sectional study was conducted at Sigatoka Subdivisional Hospital (SSH) in Fiji in July-August, 2018 using a selfstructured questionnaire to test KAP of 225 patients. The inclusion criteria were confirmed T2DM patients (Fijian citizens) with CKD, aged 30 years or above and attending Special Out-Patient's Department (SOPD) at SSH. Independent t-test and ANOVA was used to test differences between demographic variable and practice score while non-parametric tests were used for knowledge and attitude. Spearman correlation and multiple linear regressions were also done. All the tests were set at $5 \%$ level of significance.

Results: The mean KAP level was high: knowledge, 23.3 (SD \pm 3.25$)$; attitude, 23.1 (SD \pm 2.73 ) and practice, 7.1 (SD \pm 2.04$)$. A high level of knowledge was seen in those with university-level education $(p<0.001)$, unemployed $(p=0.05)$ and high average monthly income $(p=0.03)$. Those aged 61-70 years had a 0.53-point lower attitude score $(p=0.05)$ than other age categories, while those $>70$ years had a 1.78point lower attitude score $(p=0.01)$ than other age categories. Fijians of Indian descent (FID) had lower attitude $(p=0.002)$ and higher practice $(p=0.001)$ scores.

Conclusion: Patients with both T2DM and CKD at SSH have high levels of KAP. Those with higher levels of education, the unemployed and those with high monthly income had higher knowledge, FID had low attitude but high practice scores, and the higher age category had

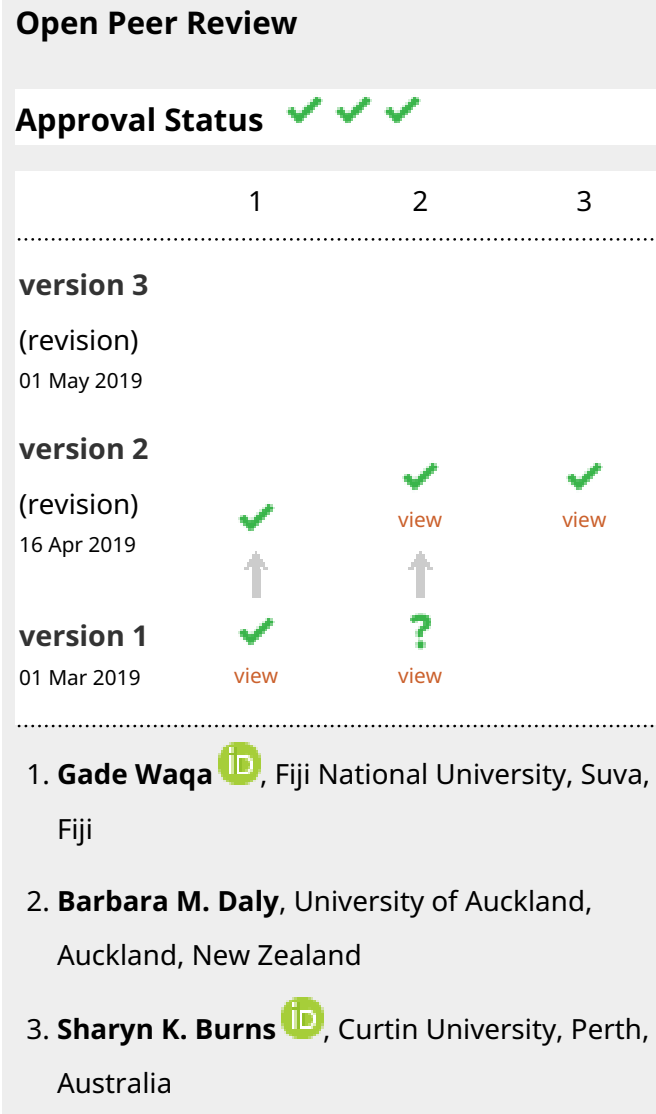

Any reports and responses or comments on the article can be found at the end of the article. 
lower attitude scores. The study identified high-risk groups for low KAP, which can become the focus of future public health intervention.

Keywords

Knowledge, Attitude, Practice, Type 2 Diabetes Mellitus, Chronic

Kidney Disease, Determinants, Fiji.

Corresponding author: Masoud Mohammadnezhad (masraqo@hotmail.com)

Author roles: Zibran MA: Conceptualization, Data Curation, Formal Analysis, Investigation, Methodology, Project Administration, Writing - Original Draft Preparation; Mohammadnezhad M: Conceptualization, Methodology, Supervision, Writing - Original Draft Preparation, Writing - Review \& Editing

Competing interests: No competing interests were disclosed.

Grant information: The author(s) declared that no grants were involved in supporting this work.

Copyright: $\odot 2019$ Zibran MA and Mohammadnezhad M. This is an open access article distributed under the terms of the Creative Commons Attribution License, which permits unrestricted use, distribution, and reproduction in any medium, provided the original work is properly cited.

How to cite this article: Zibran MA and Mohammadnezhad M. Determinants of knowledge, attitude and practice in patients with both type 2 diabetes and chronic kidney disease in Fiji [version 1; peer review: 1 approved, 1 approved with reservations] F1000Research 2019, 8:239 https://doi.org/10.12688/f1000research.18188.1

First published: 01 Mar 2019, 8:239 https://doi.org/10.12688/f1000research.18188.1 


\section{Introduction}

Type 2 diabetes mellitus (T2DM) is characterized by fasting blood glucose of more than $7 \mathrm{mmol} / \mathrm{L}$ or random blood sugar of more than $11 \mathrm{mmol} / \mathrm{L}$ in the presence of symptoms of increase thirst/hunger, frequent urination and weight loss (O'Neil et al., 2012). T2DM is the seventh-leading cause of death globally (Zheng et al., 2018), and various complications arise as a consequence of this disease - one of the major ones being chronic kidney disease (CKD) (Idris et al., 2018; Yakush Williams, 2017). $\mathrm{CKD}$, the ninth-leading cause of deaths globally (Rifkin et al., 2012), is defined as estimated glomerular filtration rate (eGFR) of less than $60 \mathrm{ml} / \mathrm{min}$ for at least 3 months (Bouchard et al., 2010). Fiji's STEP-wise Surveillance Report (STEPS) of 2011 showed that $15.6 \%$ of the population had raised fasting blood sugar (Snowdon \& Tukana, 2011). This is quite worrying, since $\mathrm{T} 2 \mathrm{DM}$ is the major cause of $\mathrm{CKD}$, accounting for $44 \%$ of all cases and hence a rise in T2DM will lead to a greater burden of CKD in Fiji (Atkins \& Zimmet, 2010). On that same note, T2DM and CKD were found to be among the top four causes of premature deaths and death and disability combined in Fiji (IHME, 2016). The final stage of CKD is very costly since it requires renal dialysis optimally three times a week and renal transplant eventually whereby cost of each dialysis session in Fiji can range from \$USD70 to USD120 (Consumer Council of Fiji, 2017). Apart from these costs, the healthcare expenses related to management of these medical conditions are borne by the government of Fiji and hence trimming these expenses via addressing these 2 diseases from a public health perspective would be beneficial (MoHMS, 2015).

The knowledge, attitude and practice (KAP) survey, which uses questionnaires to gather information from the patients on specific aspects of certain conditions (Kaliyaperumal, 2004), is a useful tool for assessing and improving control of patient's disease, delaying associated complications (Ghannadi et al., 2016), influencing better health policy (Stanifer et al., 2015) and increasing awareness for disease prevention. Various factors have been linked to level of KAP in T2DM patients with CKD; for instance female gender has been linked to poor knowledge but good attitude (Yusoff et al., 2016) while males have been shown to have good practice (Stanifer et al., 2016). Similarly, employed participants were found to have higher knowledge while married ones had high attitude and practice (Mutiso et al., 2011; Thirsk et al., 2014; Yusoff et al., 2016). Consequently, a KAP survey of individuals with T2DM and CKD will provide an insight on the current status of the level of KAP and its determinants in a referral hospital in Fiji- Sigatoka Sub-divisional Hospital (SSH), which can be utilized to inform public health programs and help target high-risk cases to improve awareness, promote selfcontrol in patients and reduce or delay complications from T2DM and CKD (Ghannadi et al., 2016).

Since, there have been no studies on KAP of T2DM patients with CKD in Fiji, this study aimed to identify the determinants of KAP in T2DM patients with CKD in Fiji in 2018. The specific objectives were to identify the level of each of the aspects of KAP and to investigate for significant links between the level of
KAP and the socio-demographical features in T2DM patients with CKD in Fiji in 2018.

\section{Methods}

\section{Design and sample}

This research applied a cross-sectional, quantitative design to identify determinants of KAP in patients with T2DM and CKD at SSH from 1st July 2018 to 31st August 2018. The inclusion criteria for the study sample were patients with confirmed T2DM plus CKD, attending in the waiting area in front of the Special Out-Patient's Department (SOPD) clinic at SSH, citizen of Fiji, age $\geq 30$ years and most importantly they had to agree to participate in the study. The exclusion criteria were patients with CKD but not T2DM, patients with any illness that jeopardizes their mental ability to participate and those who were not interested in taking part in the study.

The study was conducted at SSH's SOPD clinic. SSH is a SubDivisional Hospital in the Western Division of Fiji and it is a secondary-level hospital which provides general outpatient services, SOPD, inpatient services, maternity, child-health, eye-care, laboratory tests, radiological examinations and pharmacy. It is the only hospital in Nadroga/Navosa Sub-division and it accepts primary referrals from its Health-Centers, while it refers cases to its tertiary hospital—Lautoka Hospital.

Purposive sampling was used, which included all the patients who attended SOPD at SSH during the study period and satisfied the inclusion and exclusion criteria. Potential sources of bias were addressed by attempting to reduce selection bias by allowing all eligible participants to be part of the study while ensuring all criteria for inclusion/exclusion are adhered to. Every participant who qualified under the study criteria was eligible for the study. As a result, from a total of 265 patients who satisfied the inclusion/exclusion criteria, a sample size of 225 was finally selected to participate in this study.

\section{Measures}

The data collection tool was the KAP questionnaire (Mohammadnezhad, 2019), which had been developed by reviewing the literature and using other similar questionnaires that have been used previously, like the CKD Screening Index (Khalil \& Abdalrahim, 2014) and KAP questionnaire developed by Stanifer et al. (2015). This questionnaire was divided into two sections: Section A contained general information on 7 factors and Section B measured the KAP aspect of T2DM patients with CKD. For the knowledge component, each item was given a score of " 2 " for a correct answer, "1" for "do not know" and "0" for incorrect response. Hence, the total scoring range for this section of 15 questions was $0-30$ for each participant. Those with a score of 0-15 were considered as "low level of knowledge", 16-22 as "medium level of knowledge" and 23 and over as "high level of knowledge" (Kim, 2008; Tekanene et al., 2018). For the attitude component, each item was given a score of " 2 " for a positive attitude, "1" for "neutral" and " 0 " for negative attitude. Hence, the total scoring range for this section of 15 questions was 0-30 for each participant. Those with a score of $0-15$ were 
considered as "low level of attitude", 16-22 as "medium level of attitude" and 23 and over as "high level of attitude" (Kim et al., 2009; Lincoln et al., 2018). For the practice component, each item was given a score of " 1 " for a positive practice and " 0 " for negative practice. Hence, the total scoring range for this section of 10 questions was $0-10$ for each participant. Those with a score of less than 5 were considered as "low level of practice" and 5 or over as "high level of practice" (Kim et al., 2008; Tekanene et al., 2018).

Before collecting the data, face validity was assessed among 10 volunteer T2DM patients with CKD who were attending the SOPD clinic at SSH and satisfied the inclusion/exclusion criteria (5 males and 5 females) to assess whether the questionnaire was legible, clear, simple, easy and understandable. The content validity was also conducted among three experts (research supervisor, co-supervisor and a Medical Registrar from Lautoka Hospital) to decide whether the content of the questionnaire met the objective of the study or not. Apart from the English version, the questionnaire (plus the information sheet and consent form (Mohammadnezhad, 2019)) was translated into two other languages (Hindi and iTaukei) by a bi-lingual translator and then cross-translated to ensure the contents of the original questionnaire matched the translated version.

\section{Data collection process}

After providing the information sheets, those who were eligible and consented for the study were given the questionnaire to either fill and return on the same day or return it later before the due-date by dropping it in the specially marked box in SOPD. The illiterate participants were assisted by the research assistant who provided non-bias support in filling the questionnaire on their behalf.

\section{Data analysis}

All the questionnaires received by 31st August 2018 were used for analysis, while the rest were classified as non-responders. The information from the questionnaire was entered in Microsoft Excel Data Sheet for cleaning and coding after which it was transferred to SPSS Version 25. The continuous variables were analyzed and expressed as means and standard deviation while the categorical variables were displayed as counts and percentages in a frequency distribution table. The Kolmogorov-Smirnov test was used to assess the normality for continuous variables. The tests of baseline differences in demographic characteristics and practice scores were done using independent t-test and ANOVA. Apart from comparing gender with KAP, all other comparisons were made using non-parametric tests to check the differences between demographic characteristics and knowledge and attitude respectively. Multiple linear regression analysis was conducted to see which independent variables were significant predictors of the dependent variable. $\mathrm{P}<0.05$ was considered to indicate statistical significance.

\section{Ethical considerations}

Ethical approval for this study was obtained from the Fiji National University College Health Research Ethics Committee (CHREC) and the Fiji National Health Research Ethics and
Review Committee (FNHRERC) - approval number 2018.128. W.D. Each participant provided their written informed consent to take part in this study.

\section{Results}

\section{Participant background}

The study sample for this research comprised of 225 participants aged 38-92 years (mean=58.6, $\mathrm{SD}=9.99$ ). Majority of the participants were in the age range of 46-60 years $(52.4 \%)$ and there was almost an equal number of male $(48.9 \%)$ and female $(51.1 \%)$ participants in this study. In terms of ethnicity, there was almost an equal number of iTaukei (48.9\%) and FID (48.4\%). In total, $48 \%$ of the study subjects had secondary-level education, $38 \%$ of the participants were employed, $80.4 \%$ were married and $67.1 \%$ of the participants had an average monthly income of $<\$ 400$ (see Table 1 ).

\section{Overall scores of participant's knowledge, attitude and practice}

Table 2 displays the overall scores for the participant's KAP. The highest score for knowledge was 30, while the mean score was

Table 1. Demographic Characteristics of Participants $(\mathbf{n}=$ 225).

\begin{tabular}{|c|c|c|c|}
\hline Variables & Categories & $\mathbf{N}$ & $\%$ \\
\hline \multirow[t]{4}{*}{ Age (years) } & $30-45$ & 18 & 8.0 \\
\hline & $46-60$ & 118 & 52.4 \\
\hline & $61-75$ & 75 & 33.3 \\
\hline & $>76$ & 14 & 6.3 \\
\hline \multirow[t]{2}{*}{ Gender } & Male & 110 & 48.9 \\
\hline & Female & 115 & 51.1 \\
\hline \multirow[t]{3}{*}{ Ethnicity } & iTaukei & 110 & 48.9 \\
\hline & Fijians of Indian Descent & 109 & 48.4 \\
\hline & Fijians of Others Descent & 6 & 2.7 \\
\hline \multirow[t]{4}{*}{ Level of Education } & Uneducated & 10 & 4.5 \\
\hline & Primary & 75 & 33.3 \\
\hline & Secondary & 108 & 48.0 \\
\hline & University & 32 & 14.2 \\
\hline \multirow[t]{3}{*}{ Employment Status } & Unemployed & 72 & 32.0 \\
\hline & Employed & 86 & 38.2 \\
\hline & Domestic Duties & 67 & 29.8 \\
\hline \multirow[t]{4}{*}{ Marital Status } & Single & 16 & 7.1 \\
\hline & Married & 181 & 80.4 \\
\hline & Divorced & 6 & 2.7 \\
\hline & Widow & 22 & 9.8 \\
\hline \multirow{4}{*}{$\begin{array}{l}\text { Average Monthly } \\
\text { Income (\$FJD) }\end{array}$} & $<400$ & 151 & 67.1 \\
\hline & $401-800$ & 40 & 17.8 \\
\hline & $801-1200$ & 18 & 8.0 \\
\hline & $>1201$ & 16 & 7.1 \\
\hline
\end{tabular}




\section{Table 2. Overall scores of participant's knowledge, attitude and practice.}

\begin{tabular}{|l|l|l|l|}
\hline Variables & Lowest score & Highest score & Mean $( \pm$ SD) \\
\hline Knowledge & 11 & 30 & $23.3( \pm 3.25)$ \\
\hline Attitude & 12 & 28 & $23.1( \pm 2.73)$ \\
\hline Practice & 2 & 10 & $7.1( \pm 2.04)$ \\
\hline
\end{tabular}

23.3 ( $\mathrm{SD} \pm 3.25$ ), which shows that the overall knowledge was high. For the attitude component, the highest score was 28 while the mean was $23.1( \pm 2.73)$ which show that the overall attitude was high. The highest score for practice was 10 while the mean was $7.1( \pm 2.04)$, which shows that the overall practice was also high.

\section{Correlation of demographic characteristics and KAP of T2DM patients with CKD}

Table 3 shows that there was a significant association between level of education and knowledge $(\mathrm{p}<0.001)$, employment status and knowledge $(\mathrm{p}=0.05)$, average monthly income and knowledge $(\mathrm{p}=0.03)$, ethnicity and attitude $(\mathrm{p}=0.002)$ and ethnicity and practice $(\mathrm{p}=0.001)$.

\section{Multiple regression analysis of independent variables with dependent variables}

Table 4 shows that none of the independent variables were a significant predictor for overall knowledge score. All the independent variables could predict only $6.7 \%$ of the total knowledge scores $\left(R^{2}=0.129\right.$, adjusted $\left.R^{2}=0.067\right)$. On the other hand, age categories of 61-70 $(\mathrm{t}=-0.664, \mathrm{p}=0.05)$ and $>70$ $(\mathrm{t}=-1.653, \mathrm{p}=0.01)$ and Ethnicity (FID: $\mathrm{t}=-3.287, \mathrm{p}=0.001)$ were significant predictors of overall attitude score. Those aged 61-70 years had a 0.53-point lower attitude score compared to other age categories (with other variables constant) while those aged $>70$ years had 1.78-point lower attitude score compared to other age categories (with other variables constant). Similarly, FID had a 1.5-point lower attitude score compared to other ethnic groups (holding other variables constant). All independent variables could predict only $2.9 \%$ of the total attitude scores $\left(\mathrm{R}^{2}=0.094\right.$, adjusted $\left.\mathrm{R}^{2}=0.029\right)$. Finally, ethnicity (FID: $t=3.714, p<0.001$ ) was the only significant predictor of overall practice score. FID had a 1.03-point higher practice score compared to other ethnicities (holding other variables constant). All independent variables could predict only $6.1 \%$ of the total practice scores $\left(R^{2}=0.123\right.$, adjusted $\left.R^{2}=0.061\right)$.

\section{Discussion}

This research had sought to identify the determinants of KAP towards causes, prevention, diagnosis, treatment and management in T2DM patients with CKD at SSH in 2018. Those aged $61-70$ years had a 0.53 -point lower attitude score $(\mathrm{p}=0.05)$ compared to other age categories, while those aged $>70$ years had 1.78 points lower attitude score $(\mathrm{p}=0.01)$ compared to those in other age categories. On the contrary, those aged $>30$ years were associated with having a good attitude in another study (Yusoff et al., 2016). White et al. (2008) noted that people aged less than
60 years had better knowledge of kidney disease but nil association with attitude was mentioned. Similarly, those aged $>60$ years were associated with having poor knowledge of renal impairment in a study from Malaysia (White et al., 2008). On that same note, age less than 60 was linked to high knowledge score in studies from Tanzania (Stanifer et al., 2016), USA (Li et al., 2014) and Iran (Roomizadeh et al., 2014). Conversely, older age was linked to higher knowledge in another article from USA (Ryder et al., 2013) while it was associated with high practice scores in the Jordan study (Khalil \& Abdalrahim, 2014).

Age is an independent variable that has been linked to various diseases in multiple studies; for instance, a rise in age is directly linked with an increased risk of cardiac events (Canto et al., 2012). Age has also been associated with KAP of diabetes, but there are few studies which have tested and found significant links between age and KAP in individuals with diabetic kidney disease (DKD) (Islam et al., 2014).

In terms of ethnicity, the current research showed that FID had significantly lower attitude scores but higher practice scores than iTaukei and Fijians of others Descent (FoD). This finding is evident in one of the aspects of practice at the daily SOPD clinics at SSH, since in Fiji's SOPD clinics, the majority of the patients attending the clinic are FID, while iTaukei patients usually default their booked clinics and thus end up in making the majority of the numbers for NCD-related admissions. Kazley et al. (2015) had found poor knowledge scores in the African Americans but there was no mention of attitude or practice (Kazley et al., 2015).

The link between ethnicity and health-related KAP is extremely important in the Pacific setting as they are usually culturally influenced and tend to prioritize behaviors practiced by their ancestors over the past generations-this means that if their ancestors had certain attitude or practice regarding a healthissue, the Pacific people are inclined to follow the same. Culture seems to play an integral part in lots of decision-making in these PICs, as preferences are governed by the ethnic roots of most of the Pacific Islanders (Ryan et al., 2010). Subsequently, understanding and identifying the specific ethnic group with low KAP in SSH would help in tailoring the suitable health campaigns which are culturally appropriate and effective. Thus, this research shows that the iTaukei ethnicity will need to be considered while drafting and designing future public health preventive programs, as these are the individuals who need assistance with KAP towards DKD at SSH.

The level of education had the strongest link with knowledge scores of the participants at SSH in 2018 whereby those with the highest level of education had higher mean knowledge scores. This result did not come as a surprise as it makes sense that the higher the level of education, the more knowledge a person will have. However, high education levels do not necessarily equate to high levels of attitude and practice (Sa'adeh et al., 2018). White et al. (2008) had also reported higher knowledge in subjects with higher education which was supported by Stanifer et al. (2016); Khalil \& Abdalrahim (2014) and Yusoff et al. (2016). 
Table 3. Correlation of demographic characteristics and KAP of T2DM patients with CKD $(n=225)$.

\begin{tabular}{|c|c|c|c|c|c|c|c|c|c|c|}
\hline \multirow[t]{2}{*}{ Variable categories } & \multirow[t]{2}{*}{$\mathbf{N}$} & \multicolumn{3}{|c|}{ Knowledge } & \multicolumn{3}{|c|}{ Attitude } & \multicolumn{3}{|c|}{ Practice } \\
\hline & & Mean & SD ( $( \pm)$ & p-value & Mean & SD ( $( \pm)$ & p-value & Mean & SD ( $( \pm)$ & p-value \\
\hline Age (years) & & & & $0.07^{*}$ & & & $0.13^{* * *}$ & & & $0.72^{\star *}$ \\
\hline $30-45$ & 18 & 23.9 & 2.11 & & 23.4 & 2.06 & & 7.0 & 2.09 & \\
\hline $46-60$ & 118 & 23.8 & 3.31 & & 23.3 & 2.67 & & 7.3 & 2.01 & \\
\hline $61-70$ & 75 & 22.8 & 2.95 & & 22.9 & 2.96 & & 7.1 & 2.11 & \\
\hline$>70$ & 14 & 21.6 & 4.50 & & 21.8 & 2.39 & & 6.6 & 1.95 & \\
\hline Gender & & & & $0.91^{* *}$ & & & $0.53^{* * *}$ & & & $0.73^{* *}$ \\
\hline Male & 110 & 23.4 & 3.19 & & 23.1 & 2.75 & & 7.2 & 2.15 & \\
\hline Female & 115 & 23.3 & 3.32 & & 23.2 & 2.72 & & 7.1 & 1.93 & \\
\hline Ethnicity & & & & $0.85^{* * *}$ & & & $0.002^{* * *}$ & & & $0.001^{* *}$ \\
\hline I-Taukei & 110 & 23.3 & 3.18 & & 23.7 & 2.69 & & 6.7 & 2.15 & \\
\hline FID & 109 & 23.4 & 3.34 & & 22.5 & 2.70 & & 7.6 & 1.82 & \\
\hline FoD & 6 & 23.3 & 3.27 & & 23.8 & 0.98 & & 6.0 & 1.67 & \\
\hline Level of education & & & & $<0.001^{\star \star *}$ & & & $0.53^{* \star *}$ & & & $0.25^{\star *}$ \\
\hline Uneducated & 10 & 23.5 & 2.80 & & 23.6 & 2.76 & & 6.8 & 2.82 & \\
\hline Primary & 75 & 22.2 & 3.52 & & 22.9 & 3.13 & & 6.8 & 2.12 & \\
\hline Secondary & 108 & 23.5 & 2.92 & & 23.1 & 2.58 & & 7.3 & 1.91 & \\
\hline University & 32 & 25.3 & 2.81 & & 23.6 & 2.19 & & 7.5 & 2.00 & \\
\hline \multicolumn{4}{|l|}{ Employment status } & \multirow[t]{4}{*}{$0.05^{\star \star \star}$} & & & \multirow[t]{4}{*}{$0.88^{\star * *}$} & & & $0.61^{* *}$ \\
\hline Unemployed & 72 & 24.1 & 3.38 & & 23.2 & 2.78 & & 7.1 & 2.02 & \\
\hline Employed & 86 & 23.1 & 2.86 & & 23.2 & 2.58 & & 7.0 & 2.19 & \\
\hline Domestic duties & 67 & 22.7 & 3.44 & & 22.9 & 2.87 & & 7.3 & 1.86 & \\
\hline \multicolumn{4}{|l|}{ Marital status } & \multirow[t]{4}{*}{$0.86^{* * *}$} & & & \multirow[t]{4}{*}{$0.85^{\star \star *}$} & & & $0.18^{* *}$ \\
\hline Single & 16 & 23.8 & 3.56 & & 23.2 & 1.80 & & 7.5 & 1.75 & \\
\hline Married & 181 & 23.4 & 3.06 & & 23.1 & 2.84 & & 7.2 & 2.00 & \\
\hline Divorced and Widow & 28 & 23.3 & 3.25 & & 23.1 & 2.44 & & 7.1 & 2.35 & \\
\hline \multicolumn{4}{|l|}{ Average monthly income } & \multirow[t]{4}{*}{$0.03^{*}$} & & & \multirow[t]{4}{*}{$0.17^{* * *}$} & & & $0.82^{* \star}$ \\
\hline$<\$ 400$ & 151 & 22.9 & 3.33 & & 22.9 & 2.78 & & 7.1 & 2.12 & \\
\hline$\$ 401-\$ 1200$ & 58 & 24.2 & 3.01 & & 23.6 & 2.73 & & 7.1 & 1.88 & \\
\hline$>\$ 1201$ & 16 & 24.2 & 2.59 & & 23.6 & 1.89 & & 7.4 & 1.97 & \\
\hline
\end{tabular}

*Kruskal-Wallis test. ${ }^{* *}$ Parametric test. ${ }^{* * *}$ Non-parametric test.

Health literacy deals with an individual's ability to obtain, read, process and understand health-related information to make applicable health decisions (Jain \& Green, 2016; Van den Broucke, 2014). The influence of health literacy on health-related decision-making helps to explain the link between knowledge and level of education as shown by this current study in SSH. As the participants of this study with higher levels of education are likely to have a better ability to comprehend medical information given to them, it seems likely that their knowledge scores would be relatively greater compared to those who have lower level of education (thus lower health literacy). The real challenge of the health sector lies in this finding, since it means that health information must be translated into the simplest terms (free of medical jargon) and made available in the widest accessible form, so as to reach the greater subset of the population who lack higher education.

Surprisingly, unemployed subjects were found to have significantly higher level of knowledge in this study, although were not associated with better attitude and practice. Stanifer et al. (2016) had found similar link between unemployed participants and knowledge (Stanifer et al., 2016). On the contrary, Yusoff et al. (2016) concluded that employed people had higher knowledge and attitude which was supported by Li et al. (2014) and Ryder et al. (2013). These are lot of conflicting information regarding employment and level of knowledge and perhaps future studies 
Table 4. Multiple linear regression tests on independent variables.

\begin{tabular}{|c|c|c|c|c|c|c|c|c|c|}
\hline \multirow[t]{2}{*}{ Variable } & \multicolumn{3}{|c|}{ Knowledge } & \multicolumn{3}{|c|}{ Attitude } & \multicolumn{3}{|c|}{ Practice } \\
\hline & B & $\mathbf{t}$ & $p$-value & B & $\mathbf{T}$ & p-value & B & $\mathbf{t}$ & p-value \\
\hline Constant & 23.24 & 13.318 & 0.00 & 24.913 & 16.655 & 0.000 & 6.892 & 6.261 & 0.000 \\
\hline \multicolumn{10}{|c|}{ Age, years (ref. 30-45) } \\
\hline $46-60$ & 0.409 & 0.491 & 0.62 & -0.069 & -0.097 & 0.92 & 0.120 & 0.229 & 0.82 \\
\hline $61-70$ & -0.127 & -0.137 & 0.89 & -0.528 & -0.664 & 0.05 & 0.009 & 0.016 & 0.99 \\
\hline$>70$ & -1.395 & -1.108 & 0.27 & -1.784 & -1.653 & 0.01 & -0.364 & -0.458 & 0.65 \\
\hline \multicolumn{10}{|l|}{ Gender (ref. Male) } \\
\hline Female & 0.118 & 0.218 & 0.83 & 0.035 & 0.075 & 0.94 & -0.241 & -0.709 & 0.48 \\
\hline \multicolumn{10}{|l|}{ Ethnicity (ref. iTaukei) } \\
\hline FID & 0.355 & 0.806 & 0.42 & -1.242 & -3.287 & 0.001 & 1.033 & 3.714 & 0.001 \\
\hline FoD & -1.526 & -1.104 & 0.27 & -0.498 & -0.420 & 0.68 & -0.944 & -1.083 & 0.280 \\
\hline \multicolumn{10}{|c|}{ Level of education (ref. uneducated) } \\
\hline Primary & -1.487 & -1.365 & 0.17 & -1.045 & -1.119 & 0.26 & 0.904 & 0.138 & 0.89 \\
\hline Secondary & -0.466 & -0.419 & 0.68 & -1.160 & -1.218 & 0.23 & 0.746 & 1.064 & 0.29 \\
\hline University & 1.203 & 0.945 & 0.35 & -1.105 & -1.012 & 0.31 & 1.348 & 1.678 & 0.09 \\
\hline \multicolumn{10}{|c|}{ Employment status (ref. unemployed) } \\
\hline Employed & -0.205 & -0.340 & 0.73 & -0.303 & -0.584 & 0.56 & -0.715 & -1.875 & 0.06 \\
\hline Domestic duties & -0.879 & -1.335 & 0.18 & -0.263 & -0.466 & 0.64 & 0.062 & 0.149 & 0.88 \\
\hline \multicolumn{10}{|c|}{ Marital status (ref. single) } \\
\hline Married & 0.608 & 0.703 & 0.48 & 0.090 & 0.121 & 0.90 & -0.199 & -0.365 & 0.72 \\
\hline Divorced/widowed & 0.046 & 0.044 & 0.97 & 0.631 & 0.698 & 0.49 & -0.790 & -1.187 & 0.24 \\
\hline \multicolumn{10}{|c|}{ Average monthly income (ref. $<\$ 400$ ) } \\
\hline$\$ 401-\$ 1200$ & 0.240 & 0.432 & 0.67 & 0.546 & 1.144 & 0.25 & -0.018 & -0.051 & 0.96 \\
\hline$>\$ 1201$ & 0.432 & 0.482 & 0.63 & 0.934 & 1.214 & 0.23 & 0.210 & 0.371 & 0.71 \\
\hline $\mathrm{R}^{2}$ & \multicolumn{3}{|l|}{0.129} & \multicolumn{3}{|l|}{0.094} & \multicolumn{3}{|l|}{0.123} \\
\hline Adjusted $R^{2}$ & \multicolumn{3}{|l|}{0.067} & \multicolumn{3}{|l|}{0.029} & \multicolumn{3}{|l|}{0.061} \\
\hline
\end{tabular}

of DKD patients locally, regionally or internationally could clarify the doubts.

Ruhm (2005) found that health-related prevention behaviors were higher in unemployed people. This analysis was made from a Behavioral Risk Factor Surveillance System (BRFSS) in USA, and could probably explain the findings of the current research whereby unemployed participants had higher knowledge levels (Ruhm, 2005). However, the attitude and practice levels could not be linked with unemployment in SSH in 2018 and thus it is difficult to use the BRFSS solely as it deals with behaviors rather than knowledge alone.

Patients with T2DM and CKD at SSH in 2018 with high average monthly income had significantly higher knowledge levels regarding DKD, although the link to attitude and practice was insignificant. Similarly, Yusoff et al. (2016) found poor knowledge in those with low family income, while Khalil \& Abdalrahim (2014) had showed that subjects with high monthly income had high practice scores. Income is one of the key pillars of socioeconomic status (SES) - the other two being occupation and education. Therefore, it makes sense if participants with high monthly income have high knowledge since the interplay between the social gradient and health literacy is quite predictable (Diamond et al., 2011; Quinlan et al., 2013).

Fiscella (2016) stated that a person's behavior is limited by their SES and hence their health-seeking behavior will change if their access to resources is increased (Fiscella, 2016). This means that the socio-economic disparities of participants with lower monthly income at SSH will need to be tackled by primary healthcare workers to influence KAP. This is not an easy task and thus may involve health and policy-making at the operational level to take into account the issues of health equality and equity. 
Strengths and limitations of the study

The strengths of the study are that this is probably the first study done in Fiji to focus on the KAP of patients with T2DM and CKD. The baseline demographical information showed almost equal representation of sample in terms of gender, ethnicity and employment status, and thus the biasness is substantially reduced. The availability of the survey tool in three languages enabled the collection of data from all the ethnic groups (FID, iTaukei and FoD).

The limitations of this study are that the sample size was very small and the lack of generalizability of the results to all the population. Due to the questionnaire being self-answered by the participants, there is also a high chance of errors or misrepresentation of information.

\section{Conclusion}

This quantitative, cross-sectional study showed that the study participants have an overall high level of KAP, with average values of $23.3(\mathrm{SD} \pm 3.25), 23.1(\mathrm{SD} \pm 2.73)$ and $7.1(\mathrm{SD} \pm 2.04)$, respectively. Those with higher level of education, unemployed and high monthly income had higher knowledge while FID had lower attitude scores but high practice scores, while the higher age category had lower attitude scores.

Consequently, this research was able to identify high-risk groups with low levels of KAP, towards whom public health interventions can be targeted in future. The results of this study can enable informed public-health policies to be made to target the specific groups with low KAP and consequently increase their KAP through well-planned, appropriate and tailored strategies that suit the identified groups. Consequently, health promotion activities are vital in improving KAP, and it is recommended for interventional studies to be conducted using the results of this study among patients to measure the effectiveness of health promotion intervention.

\section{Data availability}

Underlying data

Open Science Framework: T2DM among CKD patients. https:// doi.org/10.17605/OSF.IO/A25GD (Mohammadnezhad, 2019). Raw data are included in the indicated file.

\section{Extended data}

Open Science Framework: T2DM among CKD patients. https://doi. org/10.17605/OSF.IO/A25GD (Mohammadnezhad, 2019).

- This project contains the following extended data:

- Questionnaire.pdf (questionnaire in each language).

- Consent Forms.pdf (in each language).

Information sheet.pdf (information for participants in each language).

Data are available under the terms of the Creative Commons Zero "No rights reserved" data waiver (CCO 1.0 Public domain dedication)

\section{Grant information}

The author(s) declared that no grants were involved in supporting this work.

\section{Acknowledgments}

We are grateful to the Sub-Divisional Medical-Officer of Sigatoka Sub-divisional Hospital, Dr Amos Zibran, for agreeing to utilize the hospital's Special Outpatient Department for the research. We thank Mrs. Sabiha Khan for her advisory input and encouragement.

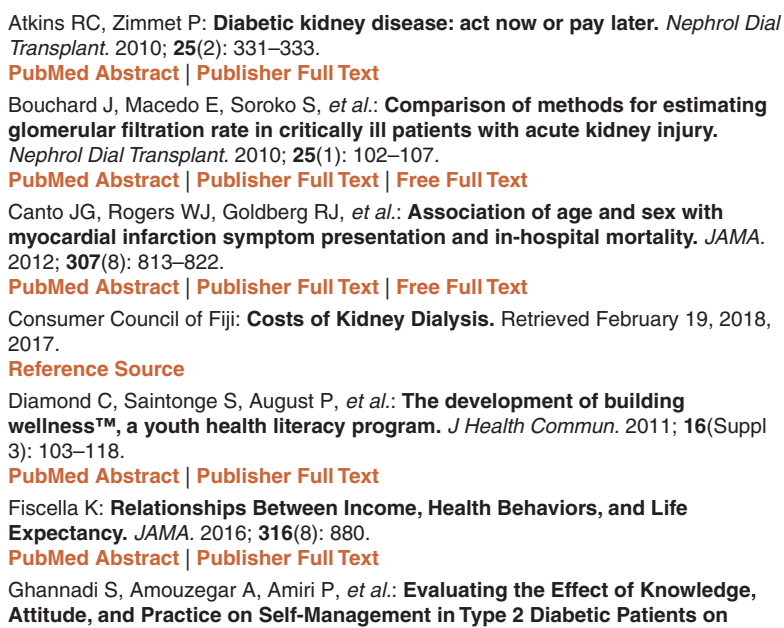

Atkins RC, Zimmet P: Diabetic kidney disease: act now or pay later. Nephrol Dial Transplant. 2010; 25(2): 331-333.

PubMed Abstract | Publisher Full Text

Bouchard J, Macedo E, Soroko S, et al.: Comparison of methods for estimating glomerular filtration rate in critically ill patients with acute kidney injury. Nephrol Dial Transplant. 2010; 25(1): 102-107.

PubMed Abstract | Publisher Full Text | Free Full Text

Canto JG, Rogers WJ, Goldberg RJ, et al:: Association of age and sex with myocardial infarction symptom presentation and in-hospital mortality. JAMA. 2012; 307(8): 813-822.

PubMed Abstract | Publisher Full Text | Free Full Text

Consumer Council of Fiji: Costs of Kidney Dialysis. Retrieved February 19, 2018, 2017.

Reference Source

Diamond $C$, Saintonge S, August $P$, et al:: The development of building wellness $^{\mathrm{TM}}$, a youth health literacy program. $J$ Health Commun. 2011; 16(Supp 3): $103-118$.

PubMed Abstract | Publisher Full Text

Fiscella K: Relationships Between Income, Health Behaviors, and Life Expectancy. JAMA. 2016; 316(8): 880.

PubMed Abstract | Publisher Full Text

Ghannadi S, Amouzegar A, Amiri P, et al.: Evaluating the Effect of Knowledge, Attitude, and Practice on Self-Management in Type 2 Diabetic Patients on

Dialysis. J Diabetes Res. 2016; 2016: 3730875. PubMed Abstract | Publisher Full Text | Free Full Text

Idris I, Tohid $\mathrm{H}$, Muhammad NA, et al.: Anaemia among primary care patients with type 2 diabetes mellitus (T2DM) and chronic kidney disease (CKD): a multicentred cross-sectional study. BMJ Open. 2018; 8(12): e025125. PubMed Abstract | Publisher Full Text | Free Full Text

IHME: Country Profile - Fiji. Retrieved February 10, 2018, from Institute of Health Metrics and Evaluation, 2016.

Reference Source

Islam FM, Chakrabarti R, Dirani M, et al:: Knowledge, attitudes and practice of diabetes in rural Bangladesh: the Bangladesh Population based Diabetes and Eye Study (BPDES). Plos One. 2014; 9(10): e110368.

PubMed Abstract | Publisher Full Text | Free Full Text

Jain D, Green JA: Health literacy in kidney disease: Review of the literature and implications for clinical practice. World J Nephrol. 2016; 5(2): 147-51. PubMed Abstract | Publisher Full Text | Free Full Text

Kaliyaperumal K: Guideline for conducting a knowledge, attitude and practice (KAP) study. AECS illumination. 2004.

Reference Source

Kazley AS, Johnson E, Simpson K, et al:: African American patient knowledge of kidney disease: A qualitative study of those with advanced chronic kidney disease. Chronic IIIn. 2015; 11(4): 245-55.

PubMed Abstract | Publisher Full Text 
Khalil A, Abdalrahim M: Knowledge, attitudes, and practices towards prevention and early detection of chronic kidney disease. Int Nurs Rev. 2014; 61(2): 237-45. PubMed Abstract | Publisher Full Text

Kim SS: Predictors of short-term smoking cessation among Korean American men. Public Health Nurs. 2008; 25(6): 516-25.

PubMed Abstract | Publisher Full Text

Kim SS, Gulick EE, Nam KA, et al.: Psychometric properties of the alcohol use disorders identification test: a Korean version. Arch Psychiatr Nurs. 2008; 22(4): $190-9$

PubMed Abstract | Publisher Full Text

Kim SS, Kim SH, Gulick EE: Cross-cultural validation of a smoking abstinence self-efficacy scale in Korean American men. Issues Ment Health Nurs. 2009; 30(2): 122-30.

PubMed Abstract | Publisher Full Text

Li C, Wen X-J, Pavkov ME, et al:: Awareness of kidney disease among US adults: Findings from the $\mathbf{2 0 1 1}$ behavioral risk factor surveillance system. $\mathrm{Am}$ J Nephrol. 2014; 39(4): 306-313.

PubMed Abstract | Publisher Full Text | Free Full Text

Lincoln J, Mohammadnezhad M, Khan S: Knowledge, Attitudes, and Practices of Family Planning Among Women of Reproductive Age in Suva, Fiji in 2017.

J Women's Health Care. 2018; 7(3): 431.

Publisher Full Text

Mohammadnezhad M: T2DM among CKD patients. 2019

http://www.doi.org/10.17605/OSF.IO/A25GD

MoHMS: Diabetes. Ministry of Health and Medical Services. Retrieved February 10, 2018. 2015.

Reference Source

Mutiso J, Kayima J, Amayo EO: Knowledge, attitudes and practices on measures to retard disease progression among chronic kidney disease patients at Kenyatta National Hospital. University of Nairobi. 2011. Reference Source

O'Neil PM, Smith SR, Weissman NJ, et al: Randomized placebo-controlled clinical trial of lorcaserin for weight loss in type 2 diabetes mellitus: the BLOOM-DM study. Obesity (Silver Spring). 2012; 20(7): 1426-36.

PubMed Abstract | Publisher Full Text

Quinlan P, Price KO, Magid SK, et al:: The relationship among health literacy, health knowledge, and adherence to treatment in patients with rheumatoid arthritis. HSS J. 2013; 9(1): 42-9.

PubMed Abstract | Publisher Full Text | Free Full Text

Rifkin DE, Coca SG, Kalantar-Zadeh K: Does AKI truly lead to CKD? J Am Soc Nephrol. 2012; 23(6): 979-84.

PubMed Abstract | Publisher Full Text | Free Full Text

Roomizadeh $\mathrm{P}$, Taheri D, Abedini A, et al.: Limited knowledge of chronic kidney disease and its main risk factors among Iranian community: an appeal for promoting national public health education programs. Int $J$ Health Policy Manag. 2014; 2(4): 161-6.

PubMed Abstract | Publisher Full Text | Free Full Text

Ruhm CJ: Healthy living in hard times. J Health Econ. 2005; 24(2): 341-363.

PubMed Abstract | Publisher Full Text

Ryan D, Talemaitoga A, Fa'amoe A, et al.: Best health outcomes for Pacific peoples: Practice implications. Medical Council of New Zealand. 2010 Reference Source

Ryder PT, Coy K, Ohmit A, et al:: Knowledge, Attitudes, Behaviors, and Beliefs about Chronic Kidney Disease in Indiana's Minority Communities: A Community-Based Survey. 2013

Reference Source

Sa'adeh $\mathrm{HH}$, Darwazeh RN, Khalil AA, et al: Knowledge, attitudes and practices of hypertensive patients towards prevention and early detection of chronic kidney disease: a cross sectional study from Palestine. Clin Hypertens. 2018; 24(1): 6.

PubMed Abstract | Publisher Full Text | Free Full Text

Snowdon W, Tukana I: Fiji - NCD Risk Factors STEPS REPORT 2011. Suva: Ministry of Health and Medical Services. 2011

Reference Source

Stanifer JW, Karia F, Voils Cl, et al.: Development and validation of a crosscultural knowledge, attitudes, and practices survey instrument for chronic kidney disease in a Swahili-speaking population. PLOS One. 2015; 10(3): e0121722.

PubMed Abstract | Publisher Full Text | Free Full Text

Stanifer JW, Turner EL, Egger JR, et al.: Knowledge, Attitudes, and Practices Associated with Chronic Kidney Disease in Northern Tanzania: A CommunityBased Study. PLoS One. 2016; 11(6): e0156336.

PubMed Abstract | Publisher Full Text | Free Full Text

Tekanene M, Mohammadnezhad M, Khan S: Knowledge, Attitude and Practice (KAP) study towards type 2 diabetes mellitus among adults who attend public health clinics in South Tarawa, Kiribati in 2017. Fiji National University, The School of Public Health and Primary Care, College of Medicine, Nursing, and Health Sciences. 2018.

Thirsk LM, Moore SG, Keyko K: Influences on clinical reasoning in family and psychosocial interventions in nursing practice with patients and their families living with chronic kidney disease. J Adv Nurs. 2014; 70(9): 2117-2127.

PubMed Abstract | Publisher Full Text

Van den Broucke S: Health literacy: a critical concept for public health. Arch Public Health. 2014; 72(1): 10.

PubMed Abstract | Publisher Full Text | Free Full Text

White SL, Polkinghorne KR, Cass A, et al:: Limited knowledge of kidney disease in a survey of AusDiab study participants. Med J Aust. 2008; 188(4): 204-208. PubMed Abstract

Yakush Williams JK: Management Strategies for Patients with Diabetic Kidney Disease and Chronic Kidney Disease in Diabetes. Nurs Clin North Am. 2017; 52(4): 575-587.

PubMed Abstract | Publisher Full Text

Yusoff DM, Yusof J, Kueh YC: Knowledge, Attitude And Practices Of The Risk For Chronic Kidney Disease Among Patients In A Tertiary Teaching Hospital. The Malaysian Journal of Nursing. 2016; 8(2): 3-11.

Reference Source

Zheng Y, Ley SH, Hu FB: Global aetiology and epidemiology of type 2 diabetes mellitus and its complications. Nat Rev Endocrinol. 2018; 14(2): 88-98.

PubMed Abstract | Publisher Full Text 


\section{Open Peer Review}

\section{Current Peer Review Status:}

\section{Version 1}

Reviewer Report 02 April 2019

https://doi.org/10.5256/f1000research.19895.r45138

(c) 2019 Daly B. This is an open access peer review report distributed under the terms of the Creative Commons Attribution License, which permits unrestricted use, distribution, and reproduction in any medium, provided the original work is properly cited.

\section{Barbara M. Daly}

School of Nursing, Faculty of Medical and Health Sciences, University of Auckland, Auckland, New Zealand

\section{General feedback}

This paper reports on knowledge, attitudes and practice or behaviours of diabetes patients with chronic kidney disease (CKD) surveyed while attending an out-patients clinic in Suva, Fiji in 2018. Despite patients having a major complication of diabetes, indicating poor control of $\mathrm{HbA} 1 \mathrm{C}$, hypertension and tobacco use, overall patients displayed a good knowledge, attitude and behavioural practice toward diabetes. This may reflect increased knowledge and practice in longterm diabetes patients who have to manage a serious complication or it may reflect a disconnect between knowledge and good self-management.

Overall, authors identify factors that relate to knowledge, attitudes and practice that may influence health behaviour and outcomes in diabetes patients with CKD. However, authors need to carefully edit this manuscript, greatly reduce the word count by deleting repetitive themes, ensure results are clear, review reference groups for multiple linear regression analyses and adhere to the usual academic writing style. Specific suggestions to improve the paper are outlined below.

Title - suggest 'Determinants of knowledge, attitude and practice in patients with type 2 diabetes and chronic kidney disease in Fiji'

\section{Abstract:}

Methods

Only refer to Fiji and elaborate later, only include the year and self-administered questionnaire.

You need to include the number of patients / total who came to the clinical and number in study.

Avoid most abbreviations in the abstract.

Remove unnecessary descriptions: name of hospital (Fijian citizens, special out-patients department, (Suva, Fiji is sufficient). 
Remove most of the statistical information and leave this to methods section.

\section{Results}

Outline numbers in study

Response rate - this is very important

Results: Out of what score i.e. 23.3 / 30.

Can you qualify 'unemployed'. For example, are these mostly students, mothers are they

collecting an unemployment benefit, are they actively seeking work. As it stands this large

group of participants do not typically resemble 'unemployed people' (around 5\% in

developed countries at the moment. Explain why so many people in the study were

\section{Conclusion}

'unemployed'. This will help you contextualise unemployed group surveyed.

Summarise the main outcomes are rather than KAP so the reader fully understands this and avoid just repeating the results.

\section{Introduction}

Please give some more details about diabetes in Fiji - almost all have type 2 I believe. What proportion have CKD (what proportion are on dialysis and is this available to al. What is the mortality rate for patients with CKD.

If you cannot find national data can you look at the data from the clinic? If not you need to suggest that this is done in a 'recommendation section' in the discussion. It is important to Grammar give readers a sense of the seriousness of the epidemic in Pacific countries.

\section{Remove first sentence}

Delete all emotive language i.e. 'this is quite worrying' instead compare $15.6 \%$ with other populations.

Paragraph two - check description. When was this developed and is it considered the best

tool to test these attributes. Is there evidence to suggest that patients who score highly are more likely to have fewer complications? Has this been used before in high-risk patients (diabetes and CKD)?

- Paragraph 3 - change beginning to: This is the first study in Fiji ...

\section{Methods}

Sample - it is important to describe this. What number of patients registered at the clinical with diabetes and CKD? Look at your sample does this represent the gender, ages, ethnicity, education etc. of the total outpatient clinic - this is what you need to discuss regarding selection bias. If Polynesian Fijians are less likely to come for appointments, are they underrepresented? Also comment on this in the limitation section especially if you cannot get these details about the total cohort of patients registered. If you cannot get data on the total cohort i.e. to check gender, age and ethnicity then you need to discuss whether the patients sampled are representative of all patients registered or enrolled in the clinic. Are all patients in Suva able to register - what about rural based patients?

\section{Unemployed - I suggest a different definition.}

It important you give more information about 'unemployed' because your finding do not fit the usual picture. A third of your sample are unemployed. How was this defined i.e. on a benefit, actively looking for work and what is the unemployment rate in Fiji. I wonder if a large proportion of these participants are students or recent graduates i.e. well educated but not employed. Are 
better-off family members or partners supporting some of them? If many are in the younger age categories this might be the case so you could have a look at the data. Alternatively, are they too sick to work? If Fiji has a very high unemployment rate then you need to explain this so that the reader knows that being unemployed is different to the usual characteristics of most unemployed people receiving a benefit. If there is a strong other characteristic such as recent university graduate then call this something else i.e. currently seeking employment or something that better defines them. It is very confusing for readers as this group are atypical. Are they largely mothers who have not returned to the workforce?

Please briefly define how 'knowledge, attitude and practice' were measured and explain the main focus of the knowledge questionnaire i.e. mostly about diabetes and $\mathrm{HbA} 1 \mathrm{c}$ control and consider including a couple of key questions. What were the main 'attitude questions' i.e. positive attitude, negative (explain to the reader) and similarly with practice i.e. include behaviours measured such as smoking. Consider given a couple of examples to illustrate the focus.

Bring the information about the questionnaire into this section. Also, cover the history of the questionnaire.

Remove unnecessary text i.e. SPOD - only include descriptions if this is necessary.

Remove 'most importantly' - no one will participate if they don't want to. Did they sign a consent form or give oral consent. We know you cannot make patients participant. What did you do to encourage patients to participate i.e. what measures to increase participation? Review exclusion criteria and avoid repeating ideas. What was mental ability i.e. an inability to complete the questionnaire i.e. be specific. It seems to me as if all patients with type 2 and CKD were invited to participate. However XX patients were unable to 'read', write or complete the questionnaire with assistance and were therefore excluded from the study. (I think only people who were incapable of completing the questionnaire were excluded so make this clear (this is good as most people were able to participate).

Para 2 - review and delete as most of this is repetition

Para 3 - describe accurately i.e. all patients who attended ... see above most of this is repetition.

A cross-sectional study is quantitative not convenient. Describe the cohort of patients eligible, were patients recruited every day during the study period. If all patients were invited, provided they could complete the questionnaire, then state this. Move comment on bias to the discussion under strengths and limitations.

Para 4 - briefly state the total score in the abstract as this is important.

Para 5 - Reduce this paragraph i.e. ... the questionnaire was piloted by... to ensure face validity. Content validity was assessed by ?? an expert panel... (you do not need all the details that you would include in a thesis).

Data collection: reduce details and write succinctly. I suggest you change 'illiterate' to 'unable to complete the questionnaire on their own' i.e. they may need glasses to read! Data analysis - how many questionnaires were handed out how many returned?

\section{Results}

Titles - You have far too many titles so need to reduce the number.

'Participant' demographic characteristics.

Factors related to knowledge etc.

Para 1 
Avoid repeating all data from the tables - summarise i.e. over half the patients were aged 46-60 years.

Avoid repeating phrases i.e. participant in this study

Define intake (indigenous or Polynesian - what do people prefer)

Do not use FID (think about the international reader) Fijian Indian / Fijian of Indian decent or the official term or what people prefer.

\section{Para 2 and 3}

Avoid repeating results. Summarise the main points.

\section{Table 4}

- Go through and review all your reference groups - these should be groups with a reasonable number of people not extreme groups with few numbers i.e. use 46-60 for age, level of education use secondary, use employed, use married, income either $<400$ or 4-800. Abbreviations should be listed under the tables $B=$ beta coefficient

\section{Para 4}

Summarise the main points i.e. what factors were associated with knowledge ... what were negatively associated. Similarly for attitude and practice

Summarise overall findings - were any factors positively associated with all three attributes, two or none.

Adjust text after you change the reference groups and reanalysis this data.

\section{Discussion}

New Para 1

Always write a summary of main findings a little like the above paragraph and use knowledge,

attitude and practice. Readers need to be able to easily understand what was measured (avoid KAP in the main summaries).

Are there any trends (see Para 4 above).

You did not measure prevention. All of these patient were already diagnosed and have a major complication (CKD). Be specific to this group of patients sampled. You cannot

New para 2 generalise your results to other diabetes patients.

Comparing main results with other study findings. Typically cite the studies with same findings then studies with opposite findings.

Avoid informal phrases i.e. 'another article from the USA' ...

Old Para 2

Delete first sentence this is irrelevant.

Focus on Type 2 diabetes with major complications i.e. CKD.

CKD is related to time since diagnosis and exposure to risk factors and other factors such as genetics, ethnicity.

\section{Para 3}

Move this to the methods section and describe the total cohort of patients with type 2 and CKD registered at the outpatients clinic.

Delete all judgemental statements.

Include barriers to good health care facility in Fiji and cite evidence. 
Include a recommendation section at the end. Include recommendations to reduce barriers to healthcare i.e. mobile clinic for rural-based patients, funding so they can attend clinic, free transport (buses to clinic), convenient time for appointments. Think about why patients do not come to appointments.

Para 4

Review this para. You are being very judgemental and have very few references. Please appreciate that all Pacific populations have been influenced by unhealthy western lifestyle changes. When you think about it if Pacific populations continued the behaviour of their ancestors they would be fit, lean, non-smoking and very physically active.

Consider how could the Government could enact healthy lifestyle changes i.e. tax on sugar, fat and tobacco?

Avoid comparing ethnic groups unless you have good evidence.

Focus on your findings on knowledge, my understanding is that this was not to ethnicity!

$\underline{\text { Para } 5}$

Move this into comparisons with other studies above.

Para 6

You did not measure health literacy you cannot bring this into your findings. Focus on the associations you found.

Remember that you found a good mean level of knowledge and yet these patients had progressive complications for diabetes. Knowledge does not always equate to better management. Highlight that despite good self-reported 'knowledge' demonstrated in the survey these were high-risk patients, with a major complication and are at high risk for further poor outcomes.

Can you comment on what changes need to occur in Fiji to reduce the epidemic of people developing diabetes and complications?

$\underline{\text { Para } 7}$

Review definition of 'unemployed'. This usually refers to people receiving an unemployment benefit and looking for work. A third of the sample are 'unemployed' so it is very different from the usual unemployed group in developed countries.

Again focus on your results and comparative studies. Avoid discussing other issues that you did not examine in your survey.

Para 8

- This is not clear. Do not bring in other questionnaires but refer to other studies that support your findings or contrast and try to explain why there might be differences between your sample and other populations.

Unemployment in the US is very different from in Fiji i.e. $<5 \%$ are unemployed in the US.

\section{Limitations}

Discuss the questionnaire. Is it an ideal questionnaire to test knowledge, attitudes and practice in the high-risk group of patients who already have CKD. Are other populations where this questionnaire has been tested the same as people registered in the outpatients in Suva? If not how might the questionnaire have been adapted. Were there knowledge, attitude and practice questions about CKD and management of risk factors?

My understanding is that the questionnaire focused on Hba1c. I believe there were very few questions about other risk factors such a hypertension, smoking and cholesterol which are very important for good management and to avoid further renal dysfunction. Point this out as a limitation of the survey tool or questionnaire. Recommend that the questionnaire may need updating to include all risk factors for complications and adapted for those with 
progressive serious complications. This tool may not be a good measure of healthy behaviour in diabetes patients with CKD i.e. has it been used in this group before i.e. very high-risk group of people with type 2. This is important for other researchers to consider. You must compare you sample with the total cohort of high risk patients in the clinic not just those in the sample (age ethnicity and gender). If your sample differs from the whole cohort then it is not representative of the total cohort.

You must be specific when discussing bias and why (which way will it increase bias) i.e. selection, information and confounding. Be clear which potential bias you are referring to. You must say why the sample size was small i.e. would there be greater differences or significant differences if the sample was larger.

Why do you say this is not generalizable? Provide you asked all diabetes patients with CKD over the study period it will be representative of those high risk patients during the study period provided equal proportions of people not come to their clinic appointments. If this was the case you need to state this provided you have data on this.

Comment on self-reported responses and the implications of this i.e. information bias toward 'politically correct' responses. Because this is not random error information bias in this case information bias would be in the positive direction.

No clinical indices were measured. For example you do not report Hba1c so you cannot report on associations between knowledge attitude, behaviours and risk factors.

New Recommendation paragraph

See suggestions above.

Mostly to reduce barriers to health care, support for patients to improve lifestyles and to better manage risk factors for complications. Most important how to improve healthy behaviours in this high risk patients group - they need intensive health care provision.

\section{Conclusion}

Summarise the main findings. Delete all data and avoid using KAP.

Move the last paragraph up to the first under conclusion and focus on the main findings.

You cannot make most of these statements as you do not know what those strategies are.

I suggest you finish on how on further research is necessary to identify strategies to improve management and outcomes for these high risk patients.

\section{Editing required}

Delete all emotive language and lay descriptions i.e. on the other hand, it did not come as a surprise, this is not an easy task, it makes sense... check the whole document and delete all of these phrases. You need to write in standard academic language.

Check all abbreviations and avoid non-standard abbreviations.

Be consistent with people in the study either use 'participants or patients - not subjects!

Check titles and avoid unnecessary descriptors i.e. type two diabetes with CKF (we know this is the patient group).

Avoid repeating participants in study. You often have this twice in one sentence or paragraph.

Check capitalisation i.e. ethnicity

Most authors now use 'among' rather than amongst.

Abbreviations should be listed under the tables ' $\mathrm{B}$ ' = beta coefficient.

Delete all judgemental statements. 
Is the work clearly and accurately presented and does it cite the current literature? Partly

Is the study design appropriate and is the work technically sound?

Yes

Are sufficient details of methods and analysis provided to allow replication by others? Yes

If applicable, is the statistical analysis and its interpretation appropriate? Partly

Are all the source data underlying the results available to ensure full reproducibility? Yes

Are the conclusions drawn adequately supported by the results?

Yes

Competing Interests: No competing interests were disclosed.

Reviewer Expertise: Quantitative research, Management of diabetes, gestational diabetes (screening and long term outcomes)

I confirm that I have read this submission and believe that I have an appropriate level of expertise to confirm that it is of an acceptable scientific standard, however I have significant reservations, as outlined above.

Author Response 09 Apr 2019

Masoud Mohammadnezhad, Fiji National University, Suva, Fiji

Thanks for your time and comments. Your comments were very useful and we tried to revise our paper based on your valuable comments. Kindly pleas find blow our response to your comments.

\section{Abstract}

1. It is better to clearly mention the setting of the study

2. The number mentioned (225) is based on the 2 months period of study for total eligible sample size - our sample size is not based on the total number of attendance

3. The abbreviations are based on the first repeat in the article and it already was reviewed by the journal editors

4. They all are study inclusion/exclusion criteria which need to be mentioned in the study method

5. A brief description of the tests used for this study is mentioned and we followed the word limitation of the journal

Results

1. Number of participants added 
2. Sentence added to abstract about response rate

3. Score added

4. Employment status was categorized only based on yes/no and further details were not asked

Conclusion

1. Conclusion corrected as per reviewer's comments

\section{Introduction}

1. Because of limited information, we have included all data that we could access and hence we do not have information about types of Diabetes in Fiji and the CKD dialysis and mortality rates in Fiji

2. Clinic data has not been audited and thus cannot be used for this study

\section{Grammar}

1. We have to define the terms used in this study

2. Emotive language changed as per reviewer comments

3. Since this is a quantitative KAP survey, a KAP questionnaire which has been developed from 2 KAP questionnaires (with Cronbach's alpha of more than 0.7), this is the best tool for the KAP measurement. We are not doing a study to check association between KAP score and its link to complications of T2DM

4. Changed as per reviewer

\section{Method}

1. The hospital used for this study is a referral hospital and thus it receives patients from all settings, ethnicities, ages, gender, etc. This study showed that the ethnic distribution was almost equal in the 2 major ethnicities thus chance of biasness is limited.

2. The questionnaire did not ask details about employment status. This study did not look at the younger age categories thus they could not be recent graduates. The participants are attending SOPD clinic and usually are older age groups.

3. More info about the KAP questions added.

4. The information details were provided. Questionnaire history already mentioned in introduction

5. SOPD needs to be mentioned as abbreviation of the clinic.

6. Most-importantly removed. The details of recruitment is mentioned in data collection process and all patients were provided consent forms and information sheets. No incentives was provided for participation but the potential benefit of participation was provided in info sheet and hence they were happy to help researcher with the study.

7. Changed as per reviewer comments

8. Para 2 - since this is a description of study setting, it cannot be deleted entirely.

9. Para 3 - corrected

10. Corrected as per comments

11. Para 4 - already added total score

12. Para 5 - corrected

13. Data collection - corrected 
14. Data analysis - corrected

\section{Results}

1. Titles - corrected

2. Para 1 - corrected

3. Para 2 and 3 - these are main finding hence need to be explained in text.

4. Table 4 - reference groups have been already identified and do not affect results. Abbreviation added

5. Para 4 - Main points summarized

\section{Discussion}

1. New para 1 added

2. New para 2 - not added but old para 1 revised

3. Old para 2 - first sentence not removed since it is used to explain the paragraph. Diabetic kidney disease is used interchangably for T2DM patients with CKD.

4. Para 3 - not moved since it is used to discuss the burden of CKD at SSH. The total cohort of patients with type 2 and CKD registered at the outpatients clinic at SSH is not available as there is no proper registration done. The comparison of FID is not a judgmental statement but others changed. Recommendation added in the end.

5. Para 4 - reviewed. Judgmental statements altered. Government statements added. Ethnicity used to show determinants of KAP hence it is used in discussion.

6. Para 5 - comparison is done in this paragraph since it follows the original pattern of discussion.

7. Health literacy mentioned to elaborate on the link between patient's ability to understand/comprehend information and their level of knowledge as a consequence. However, knowledge part added as per reviewer comments. Fijis changes added as per comments.

8. Para 7 - unemployment details were not asked further in the main questionnaire hence cannot change it now. Other issues have been discussed despite not being examined in this study since they help to connect the points that have been identified in this research.

9. Para 8 - The other questionnaire is a reference to discuss the topic in the paragraph. Sample differences have been explained in the latter paragraphs.

\section{Limitation}

1. The questionnaire was ideal as its validity and reliability have been mentioned. The other settings where KAP questionnaire have been tested are developing countries similar to Fiji. The KAP questions looked at both T2DM and CKD.

2. The other risk factors were not included in the questionnaire since the focus was only T2DM and its link to CKD. Additionally, T2DM is the major cause of CKD thus this link was tested in the questionnaire. Other behavioral risk factors were not deliberated.

3. It is difficult to compare my sample with the other cohorts in the clinic since there is no register to show the registered cases of high risk. The paper-based record keeping used in the clinic used for this study does not have any specific book to record all its cases by diagnosis and so forth.

4. Biasness explained

5. Sample size explanation added 
6. Generalizability portion edited

7. Information bias added as per comment

8. Comment added to limitation

\section{Conclusion}

1. Main findings summarized. Changes made as per comments

2. Last paragraph moved to first

3. Statements revised

4. Changes made

\section{Recommendation}

1. New paragraph on recommendation added

Competing Interests: There is no conflict of interest.

\section{Author Response 24 Apr 2019}

\section{Masoud Mohammadnezhad, Fiji National University, Suva, Fiji}

Thanks you for your comments and suggestions. We corrected as per your comments. We also changed the sentence structure as you advised.

Competing Interests: There is no any conflict of interest.

Reviewer Report 27 March 2019

\section{https://doi.org/10.5256/f1000research.19895.r45137}

(C) 2019 Waqa G. This is an open access peer review report distributed under the terms of the Creative Commons Attribution License, which permits unrestricted use, distribution, and reproduction in any medium, provided the original work is properly cited.

\section{Gade Waqa}

Fiji National University, Suva, Fiji

The authors utilized a self-structured questionnaire to test KAP of 225 patients at Sigatoka Subdivisional Hospital in Fiji, and used independent t-test and ANOVA to test the differences between demographic variable and practical score while non-parametric tests were used for knowledge and attitude which allowed guidance to promote effective public health interventions to high risk groups. The power of using the survey tool in three languages was demonstrated through the high response rate, although the sample size was very small that lack the generalization of the results to all the population.

It would be interesting in the discussion to compare this findings to any Fiji findings with other low 
income countries, including in the region if that is available.

Clarification is needed regarding definitions of the three ethnic groups since the results are discussed using the different ethnicity category, as usually data for Fiji is based on three groupings.

The method and discussion both mention the problem of poor knowledge and education level affecting data, yet the issue is not really explored as to its possible impact on the outcomes of the analysis. What are the implications of this? This should be discussed in the discussion section.

The discussion focuses only on ethnic differences with KAP, would it be possible to also discuss the gender differences with KAP? It is interesting that many aspects of lifestyle are better in females than males according to STEPS 2002, and this should be discussed.

Is the work clearly and accurately presented and does it cite the current literature? Yes

Is the study design appropriate and is the work technically sound?

Yes

Are sufficient details of methods and analysis provided to allow replication by others? Yes

If applicable, is the statistical analysis and its interpretation appropriate?

I cannot comment. A qualified statistician is required.

Are all the source data underlying the results available to ensure full reproducibility? Yes

Are the conclusions drawn adequately supported by the results?

Yes

Competing Interests: No competing interests were disclosed.

Reviewer Expertise: NCD risk factors, health behavioral changes, policy analysis

I confirm that I have read this submission and believe that I have an appropriate level of expertise to confirm that it is of an acceptable scientific standard.

Author Response 09 Apr 2019

Masoud Mohammadnezhad, Fiji National University, Suva, Fiji

Thanks for your time and comments. I would like to respond to your comments as below:

1. No other similar KAP studies on T2DM patients with CKD was found that was done in other countries in the Western Pacific Region

2. The 3 ethnic groups used are the I-Taukei, Fijians of Indian Descent and Fijian of 
Others Descent. Since the inclusion criteria included Fiji citizens only, the above 3 groups of people would qualify for the study.

3. Poor education level affecting data has not been discussed in detail as this was not the main objective of this study

4. Gender differences in KAP did not show any significant differences and hence was not discussed.

Competing Interests: There is no conflict of interest.

The benefits of publishing with F1000Research:

- Your article is published within days, with no editorial bias

- You can publish traditional articles, null/negative results, case reports, data notes and more

- The peer review process is transparent and collaborative

- Your article is indexed in PubMed after passing peer review

- Dedicated customer support at every stage

For pre-submission enquiries, contact research@f1000.com 